\title{
Fabrication and Experimental Analysis of Adiabatic Vortex Tube
}

\author{
K. Kiran Kumar Rao ${ }^{1}$, Dr. Pradeep G R C ${ }^{2}$, Dr. Ramesh A ${ }^{3}$, K. Prabhakar ${ }^{4}$ \\ ${ }^{I}$ Department of Mechanical Engineering, Gates Institute of Technology, Gooty, Anantapur (Dist), India. \\ ${ }^{2}$ Department of Mechanical Engineering, Gates Institute of Technology, Gooty, Anantapur (Dist), India. \\ ${ }^{3}$ Department of Mechanical Engineering, Principal Gates Institute of Technology, Gooty, Anantapur (Dist), \\ India. \\ ${ }^{4}$ Department of Mechanical Engineering, Gates Institute of Technology, Gooty, Anantapur (Dist), India.
}

\begin{abstract}
The vortex tube creates a vortex from compressed air and separates it into two air streams - one hot and one cold. This can be done by either a counter flow (or) a unit flow arrangement. In a vortex tube, the incoming air is separated into two streams, one stream rejects energy and hence become colder than the incoming air while the other receives the rejected energy and thus it has temperature elevated. The fabrication and experimental investigation was carried out based on different materials of Hot tubes like Mild steel, Aluminium and Copper used in fabrication by that the maximum hot air temperature and minimum cold air temperature were found. The fabrication and experimental investigation was carried out based on nozzle 8 $\mathrm{mm}$ diameter and orifice $6 \mathrm{~mm}$ diameter used in fabrication by that the maximum hot air temperature and minimum cold air temperature were found and by using same L/D ratio 22 with adiabatic process of Hot tube.
\end{abstract}

Keywords: Energy separation process, Ranque -Hilsch vortex tube Copper, Mild steel and Aluminium

\section{Introduction}

Vortex tube is a simple device, which can cause energy separation. The principle of vortex tube is vortices produced by tangential velocity as a main driving force for the energy separation in the vortex tube. It consists of nozzle, vortex chamber, separating cold plate, hot valve, and hot and cold end without any moving parts. In the vortex tube, when works, the compressed air expands in the nozzle, then enters vortex tube tangentially with high speed, by means of whirl, the inlet air splits in low pressure hot and cold temperature streams, one of which, the peripheral air, has a higher temperature than the initial air, while the other, the central flow, has a lower temperature.

The physical mechanism inside an operating vortex tube can be observed physically, but difficult to explain. Compressed air is sent through the inlet nozzle (Figure 1). Swirl generators at the inlet plane create the vortex motion inside the tube. As the vortex moves along the tube, a temperature separation is formed. Hot air moves along the tube periphery, and cold air is in motion in the inner core. The hot air is then allowed to exit through the cone valve at the far end of the tube, while the cold air outlet is next to the inlet plane. This resulting radial temperature separation inside the vortex tube is also called the Ranque-Hilsch effect, named after its pioneers.

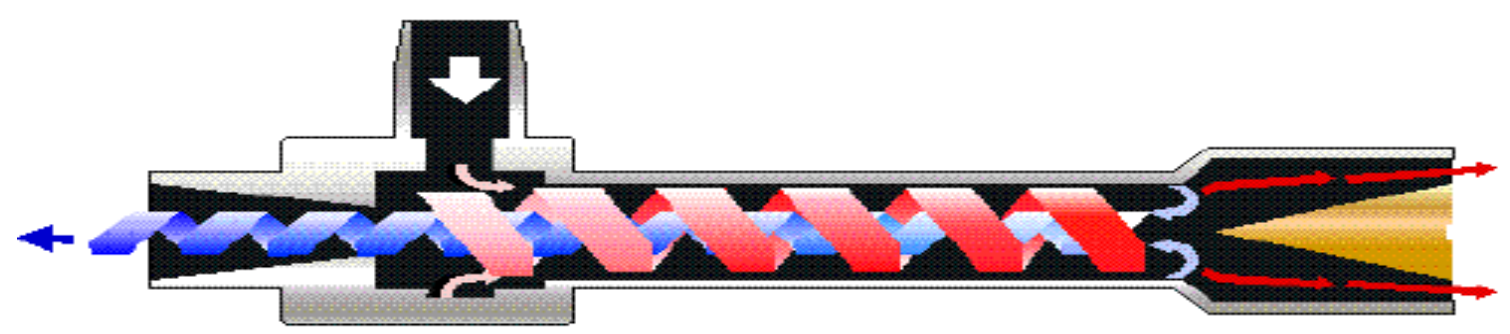

Figure 1: Vortex tube schematic

A compressed air is passed through the nozzle as shown in figure1. Here air expands and acquires high velocity due to particular shape of the nozzle. A vortex flow is created in the chamber and air travels in spiral motion along the periphery of the hot side. Then, the rotating air is forced down the inner walls of the hot tube at speeds reaching. The valve restricts this flow. When the pressure of the air near the valve is made more than the outside by partly closing the valve, a reversed axial flow through the core of the hot side starts from highpressure region. During this process, energy transfer takes place between reversed stream and forward stream and therefore air stream through the core gets cooled below the inlet temperature of the air in the vortex tube while the air stream in forward direction gets heated. The cold stream is escaped through the diaphragm hole into the cold side, while hot stream is passed through the opening of the valve. By controlling the opening of the valve, the quantity of the cold air and its temperature can be varied.. The air enters the main tube through the 
nozzle and forms a free vortex. Due to the centripetal acceleration, the vortex travels along the periphery of the tube and when it reaches the throttle valve, the rotation almost ceases, so there is a point of atmospheric pressure, a reverse axial flow starts. This flow comes into contact with the free vortex, which is moving with the increasing speed therefore the axial stream forms a forced vortex. The energy required maintaining the forced vortex in the reversed axial flow stream is supplied by the force vortex at the periphery.

Therefore, there is flow of energy (momentum) from the peripheral layer of air to the reversed axial flow stream at the axis. The rotational velocity of the free vortex at the periphery decreases gradually from the plane of the nozzle to the plane of the valve; therefore there is a relative sliding between the two adjacent airplaned, which are moving towards the valve. The result of this is a continuous transfer of energy from the plane of the nozzle to that of the valve. This gives the explanation why the heating of the air takes place as it proceeds towards the valve. The transfer energy from the inner core (from the region of forced vortex) to the periphery (into the region of free vortex) has not been explained satisfactorily. Theories abound regarding the dynamics of a vortex tube. Here is one widely accepted explanation of the phenomenon: Compressed air is supplied to the vortex tube and passes through nozzles that are tangent to an internal counter bore. These nozzles set the air in a vortex motion. This spinning stream of air turns $90^{\circ}$ and passes down the hot tube in the form of a spinning shell, similar to a tornado.

Vortex Tube behaves in a very predictable and controllable way. When compressed air is released into the tube through the vortex generator, we get hot air out of one end of the tube and cold air out the other. A small valve in the hot end, adjustable with the handy control knob, lets adjust the volume and temperature of air released from the cold end. The vortex generator - an interchangeable, stationary part - regulates the volume of compressed air, allowing altering the air flows and temperature ranges can produce with the tube. "Cold Fraction": an important term for understanding Vortex Tube Performance. "Cold Fraction" is the percentage of input compressed air that's released through the cold end of the tube. As a rule of thumb, the less cold air release, the colder the air will be adjusting the cold fraction with the control knob. Cold fraction is also a function of the type of vortex generator that's in the tube, i.e., a "high cold fraction" or "low cold fraction" generator.

\section{Fabrication Of Vortex Tube}

The vortex tube consists of the following components:

a. Main body b. Cold tube c. Hot tube d Inlet tube e. Control valve f. Diaphragm g. Nozzle h. Chamber

2.1 Main Body:

For manufacturing of main body Used $75 \mathrm{~mm}$ dia and $70 \mathrm{~mm}$ length ingot of MS material Then it is turned to a diameter $70 \mathrm{~mm}$ and length $60 \mathrm{~mm}$. internal threats of 14 TPI are cut throughout the length ,towards the hot tube side and right side threads are provided for fixing the hot pipe and cold pipe.

To provide inlet connection, drilled to a diameter of $20 \mathrm{~mm}$ and 16 TPI threads are cut. In order to facilitate convenient holding of inlet tube, shaping is done around the $20 \mathrm{~mm}$ diameter of the main body.

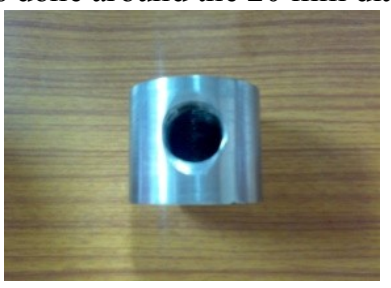

Plate No:2.1

\section{2cold Tube}

Using Mild steel piece of $85 \mathrm{~mm}$ length and $40 \mathrm{~mm}$ diameter ingot does this. This is turned to a length of $75 \mathrm{~mm}$ and $32 \mathrm{~mm}$ diameter. 14 TPI threads are cut on the outer periphery of the tube to a length of $25 \mathrm{~mm}$, which is connected to main body. After this internal taper turning is done towards the part fixed to main body with small diameter $15 \mathrm{~mm}$ and big diameter $27 \mathrm{~mm}$ to a length of $75 \mathrm{~mm}$.

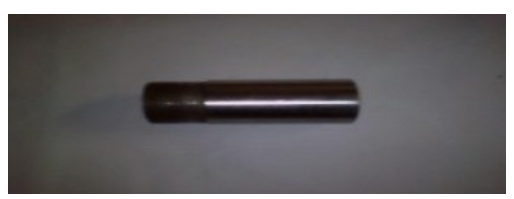

Plate No:2.1

\subsection{Hot Tube}


1. Mild Steel material of size $20 \mathrm{~mm}$ diameters and $300 \mathrm{~mm}$ length is used. First the material is turned to a diameter of $13 \mathrm{~mm}$ throughout the length $285 \mathrm{~mm}$. The external threading of 14 TPI of the part that is attachable to main body is executed to the length of $40 \mathrm{~mm}$ and threads of 14 TPI up to $25 \mathrm{~mm}$ are machined.

2. Aluminium material of size $20 \mathrm{~mm}$ diameters and $300 \mathrm{~mm}$ length is used. First the material is turned to a diameter of $13 \mathrm{~mm}$ throughout the length $285 \mathrm{~mm}$. The external threading of 14 TPI of the part that is attachable to main body is executed to the length of $40 \mathrm{~mm}$ and threads of 14 TPI up to $25 \mathrm{~mm}$ are machined.

3. Copper material of size $20 \mathrm{~mm}$ diameters and $300 \mathrm{~mm}$ length is used. First the material is turned to a diameter of $13 \mathrm{~mm}$ throughout the length $285 \mathrm{~mm}$. The external threading of 14 TPI of the part that is attachable to main body is executed to the length of $40 \mathrm{~mm}$ and threads of $14 \mathrm{TPI}$ up to $25 \mathrm{~mm}$ are machined.

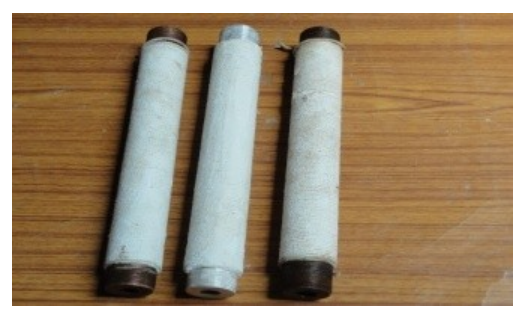

Plate no:2.3

\subsection{Inlet Tube}

Mild steel material of size $70 \mathrm{~mm} \mathrm{X} 30 \mathrm{~mm}$ is turned throughout to a diameter of $25 \mathrm{~mm}$ and step turned the ends to $20 \mathrm{~mm}$ diameter up to $14.5 \mathrm{~mm}$ length on both sides. $14.5 \mathrm{~mm}$ step turned part of the tube is threaded to $16 \mathrm{TPI}$, which is fitted over a main body. Then a hole of $9 \mathrm{~mm}$ is drilled throughout axially.

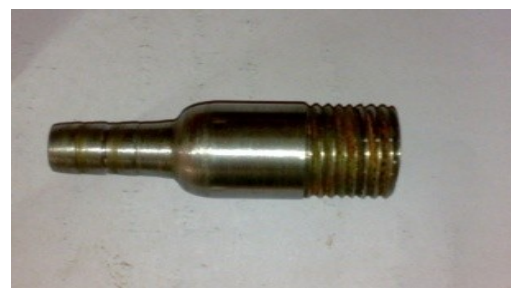

\subsection{Control Valve}

plate no:2.4

The importance of control valve lies in building up a pressure, which causes flow through a diaphragm. There will be a stagnation zone should not disturb the flow pattern in chamber extension. Hence the hot tube is inserted between the extension and the valve. In long tube the vortex motion almost ceases by the time air reaches the valve. For a short tube vortex proceeds past the valve almost undistributed, if the needle valve is set along the axis. The globe valve creates the turbulence and mixing. This is the reason because of which we use the control valve perpendicular to the hot tube axis.

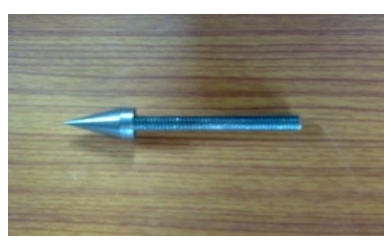

plate no:2.5

\subsection{Diaphragm}

Diaphragm is the most important part to be manufactured in the vortex tubes. It is manufactured by using Mild steel material size $15 \mathrm{~mm}$ thicknesses and $40 \mathrm{~mm}$ diameter is taken and it is turned to $32 \mathrm{~mm}$ diameter and $13 \mathrm{~mm}$ thickness. The Diaphragms are manufactured as diameter $6 \mathrm{~mm}$

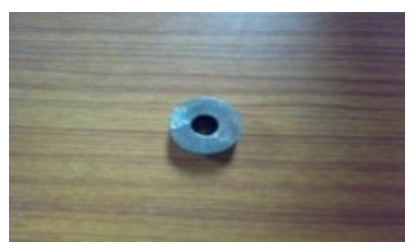

Plate no:2.6 
The nozzle is manufactured by using a Mild steel material of thickness $15 \mathrm{~mm}$ and diameter $40 \mathrm{~mm}$. This Mild steel piece is turned to a diameter of $32 \mathrm{~mm}$. Central hole is drilled to a diameter of $20 \mathrm{mmand}$ tangential cut opening $8 \mathrm{~mm}$ by using a drill bit. A tangential cut is given to the nozzle by using hacksaw blade.

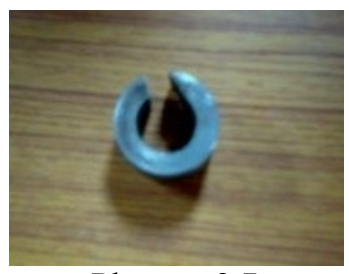

Plate no: 2.7

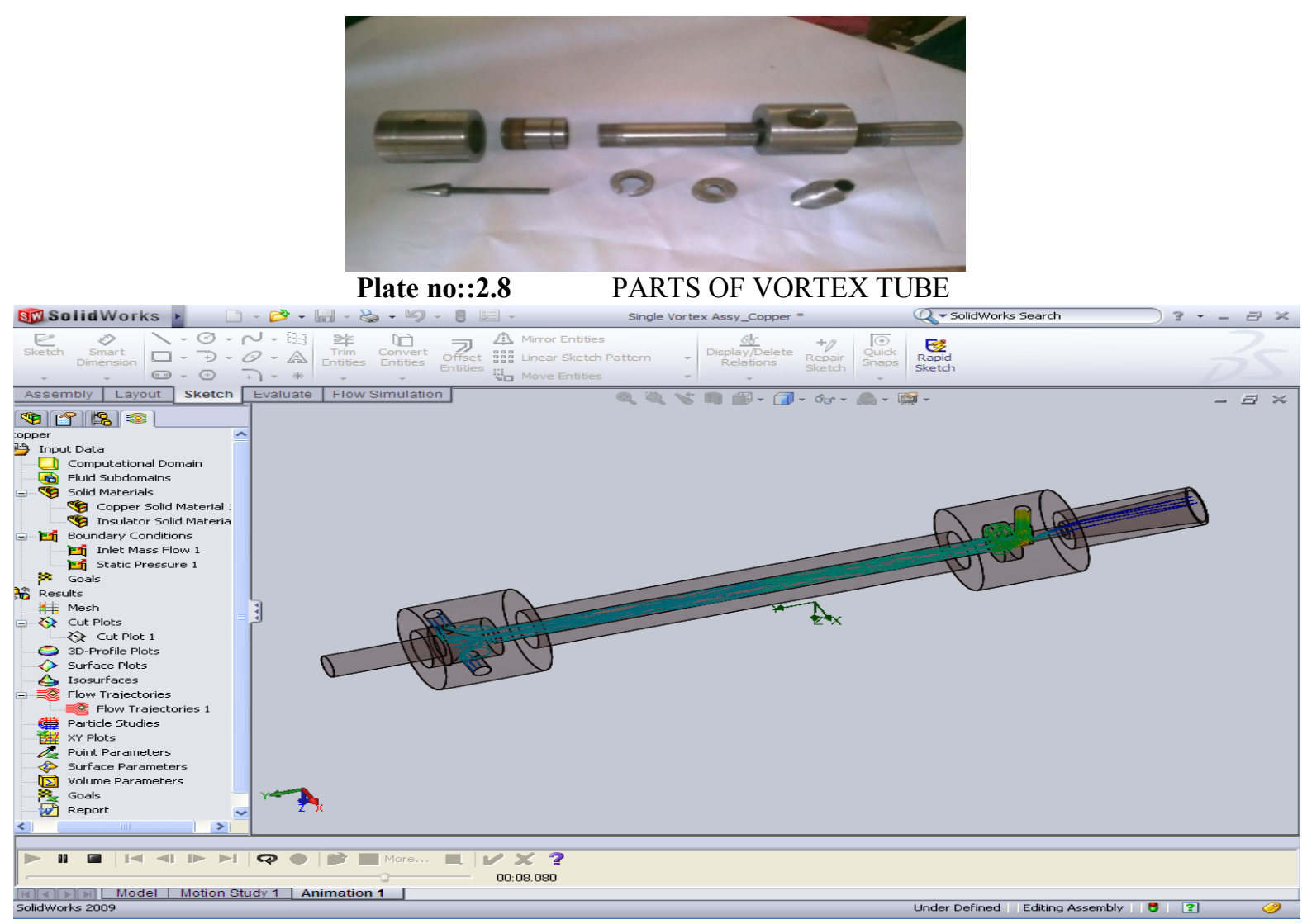

Plate no:2.8.1 FLOW TRAJECTORY OF VORTEX TUBE

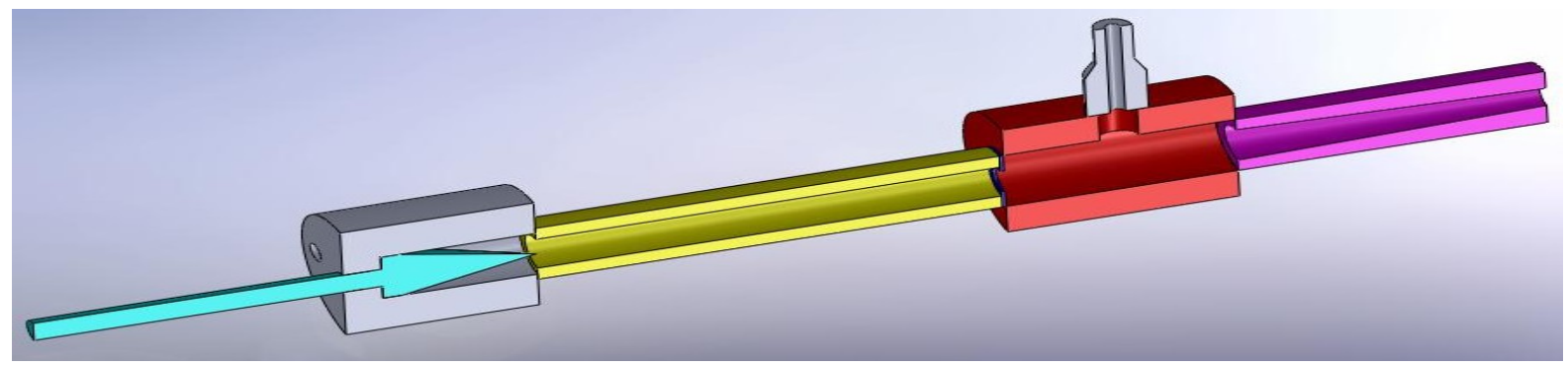

Plate no:2.8.2 SECTIONAL VIEW OF VORTEX TUBE

\section{Properties Of Materials}

\section{Mild Steel}

The calculated average industry grade mild steel density is $7861.093 \mathrm{~kg} / \mathrm{m} 3$. Its Young's modulus, a measure of its stiffness is around $210,000 \mathrm{M} \mathrm{Pa}$.

A moderate amount of carbon makes this steel different from other types. Carbon atoms get affixed in the interstitial sites of the iron lattice, making it stronger and harder. However, the hardness comes at the price of a decrease in ductility. 
Compared to other types of steel, this type is ideal for welding purposes, as it conducts electric current effectively without tarnishing the metal surface in any way.

Mild steel has ferromagnetic properties, which make it ideal for manufacture of electrical devices and motors. It yields itself easily to magnetization.

Unlike other grades of carbon steel, which tend to be brittle, mild steel is hard, yet malleable, making it the ideal choice for the construction of pipelines, construction materials and many other daily use products like cookware.

Mild steel can be machined and shaped easily due to its inherent flexibility. It can be hardened with carburizing, making it the ideal material for producing a range of consumer products.

The high amount of carbon also makes it vulnerable to rust. Naturally, people prefer stainless over mild steel, when they want a rust free technology. It is also used in construction as structural steel, besides finding applications in the car manufacturing industry

\subsection{Aluminium}

Is a strong, malleable metal element, has a low density, is a good conductor of heat and electricity, can be polished to give a highly reflective surface.

\section{3copper}

Copper is an excellent electrical conductor. Most of its uses are based on this property or the fact that it is also a good thermal conductor. However, many of its applications also rely on one or more of its other properties. For example, it wouldn't make very good water and gas pipes if it were highly reactive. On this page, we look at these other properties:

a good electrical conductor, a good thermal conductor, corrosion resistant. antibacterial, easily joined ductile, tough , non magnetic, attractive colour, recyclable ,catalytic

4.1 Mild Steel

IV. Analysis Of Vortex Tube

Length of the Hot pipe $=285 \mathrm{~mm}$ Diameter of the hot pipe $=13 \mathrm{~mm} \mathrm{~L} / \mathrm{D}$ ratio $=22$ Room Temperature $=37{ }^{0} \mathrm{C}$

\begin{tabular}{|l|l|l|l|l|l|}
\hline SL. NO & $\begin{array}{l}\text { Diameter } \\
\text { of the } \\
\text { NOZZLE } \\
(\mathrm{mm})\end{array}$ & $\begin{array}{l}\text { Diameter } \\
\text { of the } \\
\text { DIAPHRA } \\
\mathrm{M}(\mathrm{mm})\end{array}$ & $\begin{array}{l}\text { PRESSUR } \\
\mathrm{E} \\
\left(\mathrm{Kg} / \mathrm{Cm}^{2}\right)\end{array}$ & $\begin{array}{l}\text { COLD } \\
\text { TEMP }{ }^{0} \mathrm{C}\end{array}$ & $\begin{array}{l}\text { HOT } \\
\text { TEMP }{ }^{0} \mathrm{C}\end{array}$ \\
\hline 1 & 8 & 6 & 4 & 15 & 35 \\
\hline 2 & 8 & 6 & 8 & 13 & 35 \\
\hline 3 & 8 & 6 & 12 & 12 & 34 \\
\hline
\end{tabular}

Table4.1

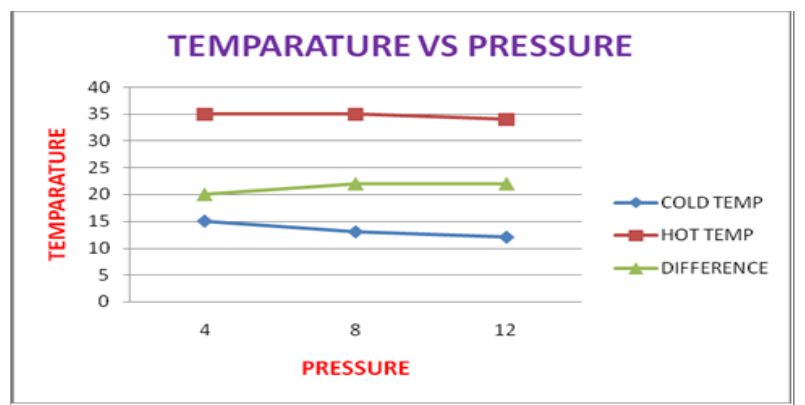

Graph no:4.1

4.2 Aluminium

Length of the Hot pipe $=285 \mathrm{~mm}$ Diameter of the hot pipe $=13 \mathrm{~mm} \quad$ L $/ \mathrm{D}$ ratio $=22$

Room Temperature $=37^{0} \mathrm{C}$

\begin{tabular}{|l|l|l|l|l|l|}
\hline NO SL. & $\begin{array}{l}\text { Diameter } \\
\text { of the } \\
\text { NOZZLE } \\
(\mathrm{mm})\end{array}$ & $\begin{array}{l}\text { Diameter of } \\
\text { the } \\
\text { DIAPHRAG } \\
\mathrm{M}(\mathrm{mm})\end{array}$ & $\begin{array}{l}\text { PRESSUR } \\
\mathrm{E} \\
\left(\mathrm{Kg} / \mathrm{Cm}^{2}\right)\end{array}$ & $\begin{array}{l}\text { COLD } \\
\text { TEMP }{ }^{0} \mathrm{C}\end{array}$ & $\begin{array}{l}\text { HOT } \\
\text { TEMP } \\
{ }^{0} \mathrm{C}\end{array}$ \\
\hline 1 & 8 & 6 & 4 & 23 & 35 \\
\hline 2 & 8 & 6 & 8 & 20 & 35 \\
\hline 3 & 8 & 6 & 12 & 14 & 35 \\
\hline
\end{tabular}

Table 4.2 


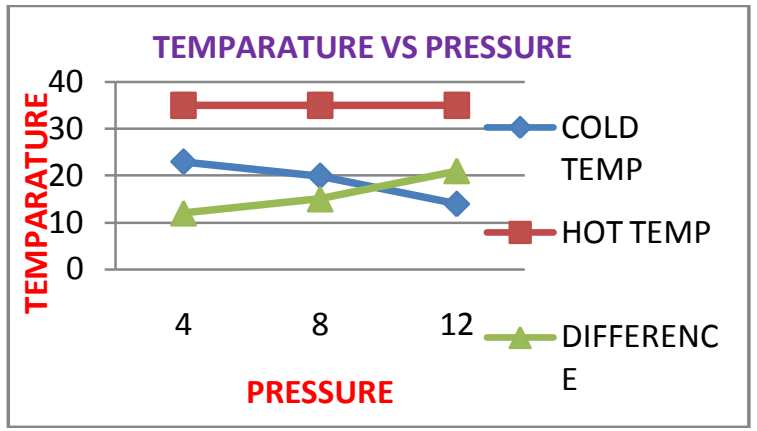

Graph no:4.2

\subsection{Copper}

Length of the Hot pipe $=285 \mathrm{~mm}$ Dia of the hot pipe $=13 \mathrm{~mm} \quad \mathrm{~L} / \mathrm{D}$ ratio $=22$ Room Temperature $=37{ }^{0} \mathrm{C}$

\begin{tabular}{|l|l|l|l|l|l|}
\hline $\begin{array}{l}\text { SL. } \\
\text { NO }\end{array}$ & $\begin{array}{l}\text { DIA OF } \\
\text { THE } \\
\text { NOZZLE } \\
(\mathrm{mm})\end{array}$ & $\begin{array}{l}\text { DIA OF THE } \\
\text { DIAPHRAGM } \\
(\mathrm{mm})\end{array}$ & $\begin{array}{l}\text { PRESSURE } \\
\left(\mathrm{Kg} / \mathrm{Cm}^{2}\right)\end{array}$ & $\begin{array}{l}\text { COLD } \\
\text { TEMP } \\
{ }^{0} \mathrm{C}\end{array}$ & $\begin{array}{l}\text { HOT } \\
\text { TEMP } \\
{ }^{0} \mathrm{C}\end{array}$ \\
\hline 1 & 8 & 6 & 4 & 17 & 32 \\
\hline 2 & 8 & 6 & 8 & 7 & 34 \\
\hline 3 & 8 & 6 & 12 & -4 & 30 \\
\hline
\end{tabular}

Table4.3

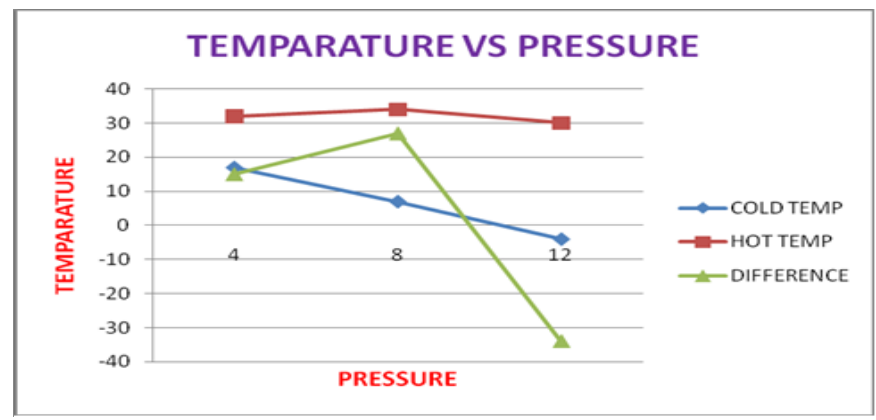

Graph no:4.3

V. Results:

5.1 We obtained best results when the length (L) $285 \mathrm{~mm}$.diameter of the hot tube (D) $13 \mathrm{~mm}$ and L/D ratio with 22 of Aluminium ,Mild steel and Copper material.

5.2. After analysis the material of Copper the minimum and maximum température has been obtained $-4^{0} \mathrm{C}$ and $30^{\circ} \mathrm{C}$ at a pressure of $12 \mathrm{~kg} / \mathrm{cm}^{2}$

5.3. After analysis the material of Aluminium and the minimum and maximum température has been obtained $14^{0} \mathrm{C}$ and $35^{\circ} \mathrm{C}$ at a pressure of $12 \mathrm{~kg} / \mathrm{cm}^{2}$

5.4. After analysis the material Mildsteel of the minimum and maximum température has been obtained $12^{\circ} \mathrm{C}$ and $34^{\circ} \mathrm{C}$ at a pressure of $12 \mathrm{~kg} / \mathrm{cm}^{2}$

5.5 After analysis the performance of Vertex tube is directly praportional to the Pressure.

\section{References}

[1]. G J Ranque. .Experiments on Expansion in a Vortex with Simultaneous Exhaust of Hot and Cold Air. Le Journal De Physique, et le Radium (Paris), vol 4, June 1933

[2]. R Hilsch. .The use of the Expansion of Aires in a Centrifugal Field as a Cooling Process. Review of Scientific Instruments, vol 13, February 1947,

[3]. C D Fulton. .Ranque Tube. Journal of the ASRE, Refrigeration Engineering, vol 58, May 1950, pp 473-479.

[4]. G W Scheper (Jr). . The Vortex Tube Internal Flow Data and a Heat Transfer Theory.. Journal of the ASRE, Refrigeration Engineering, vol 59, October 1951,

[5]. J P Hartnett and E R G Eckert. .Experimental Study of the Velocity and Temperature Distribution in a High Velocity Vortex Tube Flow. Transactions of ASME, vol 79, May 1957,

[6]. B B Parulekar. .The Short Vortex Tube.. Journal of Refrigeration, vol 4, 1961,

[7]. R B Aronson. .The Vortex Tube: Cooling with Compressed Air.. Journal of Machine Design, December 1976, pp 140-143.

[8]. J E Lay. .An Experimental and Analytical Study of Vortex Flow and Temperature Separation by Superposition of Spiral and Axial Flow, Part 1 and Part 2.. ASME Journal of Heat Transfer, vol 81, no 3, August 1959, pp 316-317.s

[9]. Windhexe

[10]. Helikon vortex separation process 
[11]. G. Ranque, Expériences sur la Détente Giratoire avec Productions Simultanées d'un Echappement d'air Chaud et d'un Echappement d'air Froid, J. de Physique et Radium 4(7)(1933) 112S.

[12]. H. C. Van Ness, Understanding Thermodynamics, New York: Dover, 1969, starting on page 53. A discussion of the vortex tube in terms of conventional thermodynamics.

[13]. Mark P. Silverman, And Yet it Moves: Strange Systems and Subtle Questions in Physics, Cambridge, 1993, Chapter 6

[14]. C. L. Stong, The Amateur Scientist, London: Heinemann Educational Books Ltd, 1962, Chapter IX, Section 4, The "Hilsch" Vortex Tube, p514-519.

[15]. J. J. Van Deemter, On the Theory of the Ranque-Hilsch Cooling Effect, Applied Science Research 3, $174-196$.

[16]. Saidi, M.H. and Valipour, M.S., "Experimental Modeling of Vortex Tube Refrigerator", J. of Applied Thermal Engineering, Vol.23, pp.1971-1980, 2003

[17]. M. Kurosaka, Acoustic Streaming in Swirling Flow and the Ranque-Hilsch (vortex-tube) Effect, Journal of Fluid Mechanics, 1982, 124:139-172

[18]. M. Kurosaka, J.Q. Chu, J.R. Goodman, Ranque-Hilsch Effect Revisited: Temperature Separation Traced to Orderly Spinning Waves or 'Vortex Whistle', Paper AIAA-82-0952 presented at the AIAA/ASME 3rd Joint Thermophysics Conference (June 1982)

[19]. Gao, Chengming. Experimental Study on the Ranque-Hilsch Vortex Tube. Eindhoven : Technische Universiteit Eindhoven. ISBN 90-386-2361-5. 